\title{
PROTOTYPE APLIKASI BERBASIS WEB SEBAGAI MEDIA INFORMASI KEHILANGAN BARANG
}

\author{
Agus Wantoro \\ Sistem Informasi, Universitas Teknokrat Indonesia \\ Jl. H.ZA Pagaralam, No 9-11, Labuhanratu, Bandarlampung \\ E-Mail : aguswantoro.ilkom@gmail.com
}

\begin{abstract}
Abstrak
Hampir setiap orang pernah mengalami kehilangan barang, baik barang pribadi maupun barang pinjaman. Hal ini tentunya sangat merugikan jika barang tidak dapat ditemukan. Sulitnya melacak keberadaan barang mencari permasalahan yang belum bisa terpecahkan. Saat ini, orang yang mengalami kehilangan barangbarang berharga upaya pencarian menggunakan iklan di beberapa media seperti koran, radio, posting di media sosial dan belum mempunyai tempat rujukan dalam pencarian barang. Cari ini dirasa masih kurang efisien karna membuhtukan biaya yang cukup mahal untuk setiap informasi yang tampilkan. Kemajuan teknologi informasi dapat dimanfaatkan sebagai media informasi pencarian barang hilang. Rancangan aplikasi berbasis website dapat dijadikan sebagai alternative aplikasi yangdapat untuk dilakukan ketahap selanjutnya untuk membantu masyakarat dalam menemukan dan memberikan informasi penemuan barang
\end{abstract}

Katakunci : Prototype, Web, Barang Hilang

\section{PENDAHULUAN}

Informasi Kehilangan adalah gambaran suatu kondisi yang dialami oleh individu ketika berpisah dengan sesuatu yang sebelumnya ada. Kehilangan merupakan pengalaman yang pernah dialami oleh setiap individu selama rentang kehidupannya. Sejak lahir, individu sudah mengalami ke-hilangan dan cenderung akan mengalaminya kembali walaupun dalam bentuk yang berbeda. Dalam agama Islam ada istilah luqhatah (barang hilang). Menurut M. Anwar luqhatah adalah harta yang ditemukan di suatu tempat dan tidak diketahui siapa pemiliknya. Kewajiban bagi yang menemukan barang hilang, orang hilang atau kehilangan lainnya adalah memberitahukan dan mengumumkan kepada masyarakat tentang penemuan barang tersebut.

Menurut Kemenkominfo (Kementerian Komunikasi dan ISSN : 2302-7339 Vol. 11 No. 12014 http://jurnal.sttgarut.ac.id

2.Informatika) mengungkapkan pengguna internet di Indonesia saat ini mencapai 63 juta orang. Dari angka tersebut, 95 persennya menggunakan internet untuk mengakses jejaring sosial. Oleh karena itu, internet merupakan wadah yang tepat untuk menampung informasi kehilangan barang. Internet memberikan jalan untuk menjalin komunikasi dalam mencari atau berbagi informasi, mulai dari keluarga, saudara, teman sampai dengan orang yang tidak dikenal sekalipun.

Saat ini jika masyarakat mengalami kehilangan barang, mereka harus melapor ke pihak yang berwajib / kepolisian yang tentunya membutuhkan proses yang cukup lama. Selain melapor, masyarakat membuat iklan seperti koran, radio, televisi yang tentunya membutuhkan biaya untuk berbagi informasi. Pesatnya perkembangan teknologi informasi dikarenakan mudahnya mengakses internet, namun sangat disayangkan apabila perkembangan dan kemajuan teknologi hanya digunakan untuk sekadar update status atau unggah foto yang ke jejaring sosial. Maka dari itu perlu adanya aplikasi yang dapat dimanfaatkan sebagai media penyedia informasi guna untuk membantu masyarakat, salah satunya media layanan informasi kehilangan barang. Berdasarkan permasalahan tersebut, perlu dikembangkan aplikasi yang dapat membantu dalam mencari barang yang hilang yang lebih mudah, cepat dan tidak membutuhkan biaya.

\section{LANDASAN TEORI}

\section{A) Tinjauan Pustaka}

Saat ini dalam perkembangan masyarakat, proses pencarian kehilangan sedikit demi sedikit mulai berkembang. Dimana individu yang mengalami proses ini mempunyai keinginan untuk memberitahukan informasi kehilangan kepada orang lain. Banyak sarana media informasi yang dapat dimanfaatkan untuk mengumumkan informasi kehilangan, contohnya seperti koran, radio, televisi, blog dan media informasi lainnya. Dengan adanya media informasi sebanyak itu, diperlukan sebuah wadah yang dapat menampung data dan informasi kehilangan secara terpusat untuk dapat dimanfaatkan oleh masyarakat sebagai media untuk mengumumkan informasi kehilangan [1]

(Devi, Thomas, 2011) "Sistem Pencarian Orang Hilang Berbasis Mobile Web Dengan Social Network Analysis". Bencana alam tidak dapat dicegah. hal yang paling sering terjadi pasca bencana alam adalah banyak orang yang terpisah dengan sanak keluarga dan kerabat. informasi mengenai kondisi dan posisi keluarga menjadi sulit untuk didapatkan. Dibutuhkan sebuah sistem yang dapat melakukan pencarian orang hilang. Sistem yang akan dibangun adalah sebuah sistem yang berbasis mobile web. Sistem ini bertujuan untuk memberikan informasi dan merelasikan antara korban baik yang meninggal, dirawat, hilang maupun yang sedang dalam pengungsian. Sistem 
ini menggunakan metode analisis jaringan sosial. Dengan adanya sistem ini diharapkan korban dapat mengetahui keberadaan sanak keluarga yang terpisah [3]

\section{B) Informasi}

Informasi adalah data yang diolah dalam bentuk yang lebih berguna dengan tujuan untuk meningkatkan pengetahuan bagi penerimanya dan bermanfaat dalam pengambilan keputusan saat ini atau mendatang (Mcleod, 2001).

\section{C) Kehilangan}

Kehilangan adalah suatu situasi aktual maupun potensial yang dapat dialamiindividu ketika berpisah dengan sesuatu yang sebelumnya ada, baik sebagian atau keseluruhan, atau terjadi perubahan dalam hidup sehingga terjadi perasaan kehilangan (Potter \& Perry, 1997). Informasi Kehilangan adalah data yang diolah untuk menggambarkan suatu kejadian yang dialami individu ketika berpisah dengan sesuatu yang pernah dimilikinya sudah tidak ada. Menurut M.Anwar luqhatah adalah barang yang ditemukan di suatu tempat dan tidak diketahui siapa pemiliknya. Kewajiban bagi yang menemukan barang hilang, orang hilang atau kehilangan lainnya adalah memberitahukan dan mengumumkan kepada masyarakat tentang penemuan barang tersebut.

\section{D) Internet}

Mereka mengemukakan internet sebagai jaringan yang saling terhubung satu sama lain yang dapat disakses oleh seluruh jaringan pada computer (El-Ansary dan Frost, 2003). Menurutnya internet ialah jaringan pada computer yang berkembang pesat dari jutaan pendidikan, bisnis dan jaringan pemerintahan yang saling terkait dengan jumlah pengguna lebih dari dua ratus Negara (O’Brien, 2003)

\section{E) Perancangan}

Tahapan perancangan (design) memiliki tujuan untuk mendesain sistem baru yang dapat menyelesaikan asalah-masalah yang dihadapi perusahaan yang diperoleh dari pemilihan alternatif sistem yang terbaik (Albahra Bin Ladjamudin, 2005). Perancangan adalah proses pengembangan spesifikasi baru berdasarkan rekomendasi hasil analisis sistem (M. Subhan, 2010).

\section{F) Kerangka Kerja}

Aktifitas penelitian dimulai dengan merumuskan masalah yang muncul untuk dijadikan acuan dalam merumuskan tujuan penelitian.Perumusan tujuan penelitian dimaksudkan agar penelitian menjadi terarah dan jelas.Setelah penelitian dirumuskan maka tahap selanjutnya dilakukan studi literatur yang dimaksudkan untuk mendukung penelitian dari sisi ilmiah. Dengan berdasarkan studi literatur dibuatlah work breakdown struktur

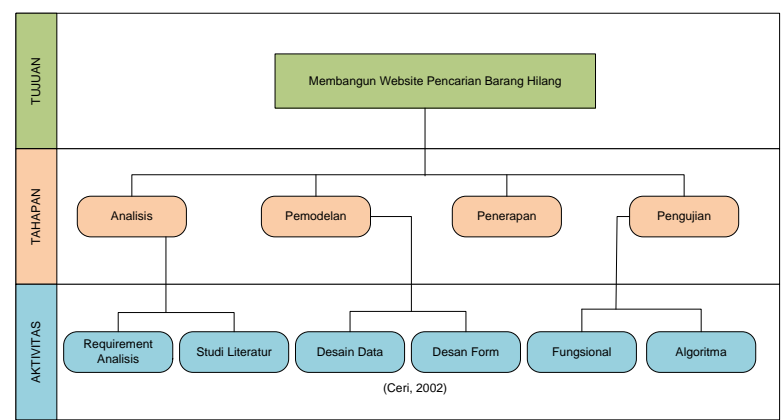

Gambar 1. Work Breakdown Structure [4]

Gambar 1. akan digunakan sebagai tahapan Analisa dan perancangan pada bab 2

\section{ANALISA DAN PERANCANGAN}

A. Analisis

1) Kebutuhan Fungsional

a. Aplikasi dapat digunakan untuk registrasi bagi pemasang barang

b. Aplikasi dapat login bagi yang pernah registrasi

c. Aplikasi dapat digunakan untuk pencarian barang bedasarkan pencarian

2) Kebutuhan Non Fungsional

a. Operasional

Hardisk 500Gb, RAM 2Gb, Layar 14", VGA 512, Mouse, Keyboard, Kecepatan Internet 100Mbps, Dreamweaver 8, PHPMyAdmin, ODBC, Appserv, Mozila Firefox

\section{b. Keamanan}

Dilengkapi user, password, nomor telepon sebagai validasi dan pernyataan

c. Infomasi

Terdapat informasi barang yang telah ditemukan berupa identitas dan lokasi barang beserta identitas pengunggah

\section{d. Tampilan}

Menggunakan bahasa indonesia dan tampilan yang mudah dipahami dan tidak terlalu banyak fitur

e. Kinerja

Aplikasi akan dibangun secara responsif, dapat diakses pada semua platform

\section{B. Perancangan Aplikasi \\ 1) Usecase Diagram}

Perancangan menggunakan tools UML usecase diagram yang terdiri dari 2 actor. Actor pertama adalah penemu barang yang berinteraksi dengan sistem. Actor penemu melakukan registrasi dan pasang informasi barang. Actor pencari hanya melakukan pencarian barang yang dicari 


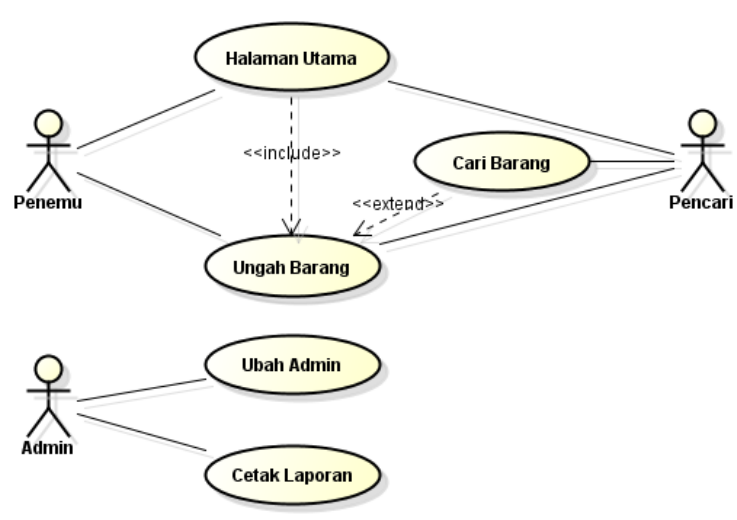

Gambar 2. Usecase Diagram Unggah dan Cari Barang

\section{2) Class Diagram}

Class diagram digunakan untuk menampilkan kelaskelas dan paket-paket di dalam system. Class diagram memberikan gambaran sistem secara statis dan relasi antar class. Terdiri dari beberapa class yaitu class menu, class utilitas, class registrasi dan class validasi

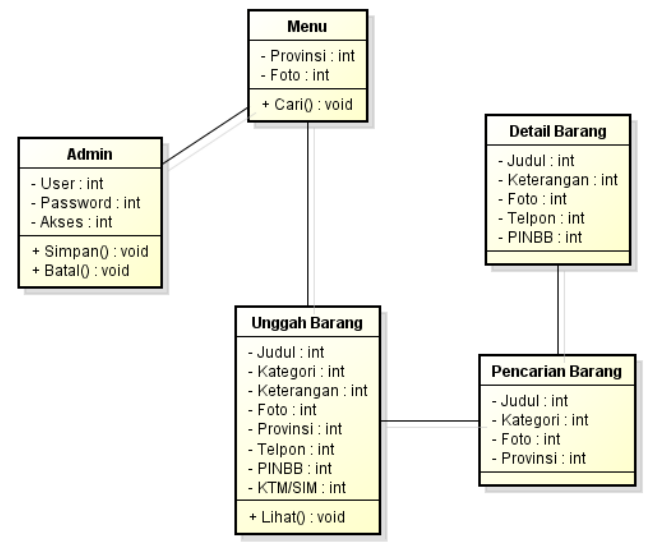

Gambar 3. Class Diagram Pencarian Barang

\section{3) Desain Data}

Tahap pembuatan data merupakan tahapan perancangan database dan relasi table.

a. Tabel Admin

Nama Database $\quad$ : dbbaranghilang.Sql

Nama Tabel : TabelAdmin

Primary Key : : User

Tabel 1. Spesifikasi Tabel Admin

\begin{tabular}{|c|l|c|c|}
\hline No & \multicolumn{1}{|c|}{ Field } & Type & Panjang \\
\hline 1 & User & Varchar & 25 \\
\hline 2 & Password & Char & 10 \\
\hline 3 & Akses & Char & 10 \\
\hline
\end{tabular}

b. Tabel Info Barang

Nama Database

Nama Tabel

: dbbaranghilang.Sql

Primary Key

$$
\text { : TabelInfoBarang }
$$

Tabel 2. Spesifikasi Tabel Info Barang

\begin{tabular}{|c|l|c|c|}
\hline No & \multicolumn{1}{|c|}{ Field } & Type & Panjang \\
\hline 1 & Judul & Varchar & 50 \\
\hline 2 & Kategori & Char & 20 \\
\hline 3 & Keterangan & Varchar & 100 \\
\hline 4 & Foto & Blob & - \\
\hline
\end{tabular}

\begin{tabular}{|c|l|c|c|}
\hline 5 & Provinsi & Varchar & 25 \\
\hline 6 & Telepone & Varchar & 24 \\
\hline 7 & PINBB & Char & 10 \\
\hline 8 & KTM & Blob & - \\
\hline 9 & Hal & Char & 10 \\
\hline
\end{tabular}

\section{3) Desain Halaman}

Halaman ini akan muncul pertama kali ketika diakses dengan pada alamat www.baranghilang.co.id. Halaman ini berisi menu memasang informasi barang dan pencarian barang berdasarkan tempat.

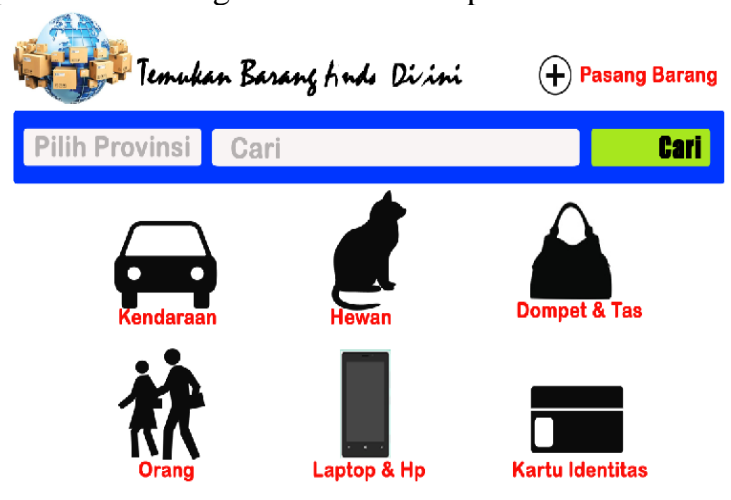

Gambar 4.3. Rancangan Halaman Menu Awal

\section{4) Halaman Admin}

Halaman ini digunakan sebagai admisnitrator untuk mengolah data seperti menambah kategori, menghapus data yang tidak sesuai dengan kategori, membuat laporan kehilangan dan laporan barang ditemukan

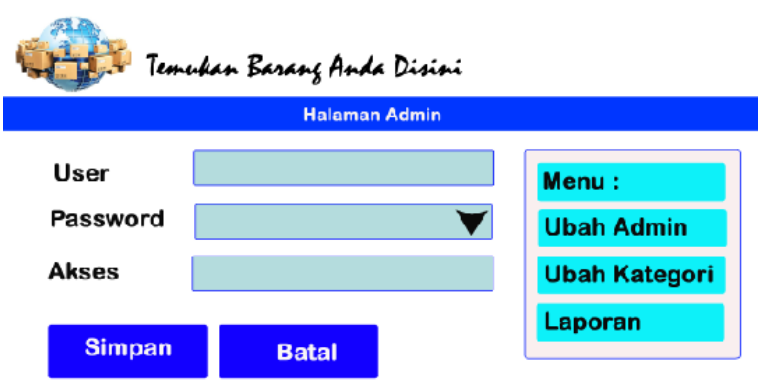

Gambar 4. Rancangan Halaman Admin

\section{5) Halaman Unggah Barang}

Halaman ini digunakan oleh penemu barang atau orang yang kehilangan barang untuk menampilkan informasi. Data yang harus input berupa judul, katergori barang, keterangan barang ditemukan atau dicari, foto, provinsi, nomor telepone, pin BB, KTP/SIM Penemu atau pencari barang dan pernyataan bahwa barang ini ditemukan bukan barang mencuri. 


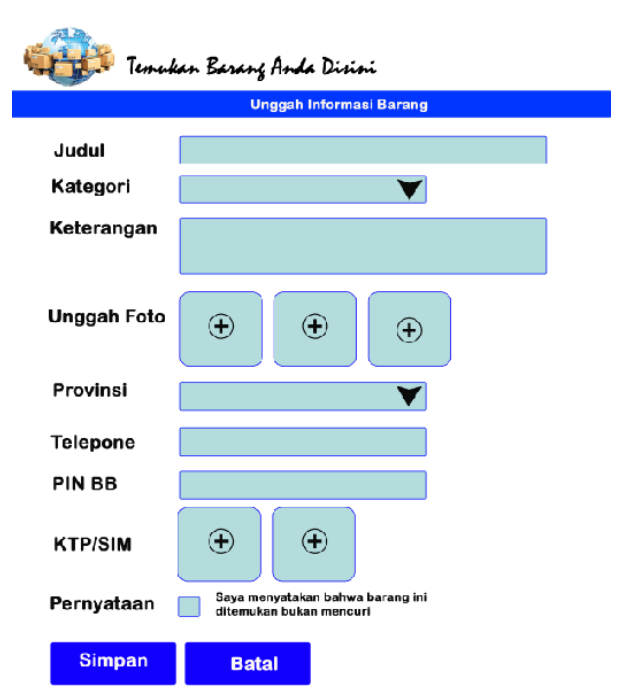

Gambar 5. Rancangan Halaman Unggah Barang

\section{Halaman Pencarian Barang}

Halaman ini digunakan oleh pencari untuk pencarian barang dengan memilih provinsi, jenis barang dan dapat mengisi kata kunci pencarian.

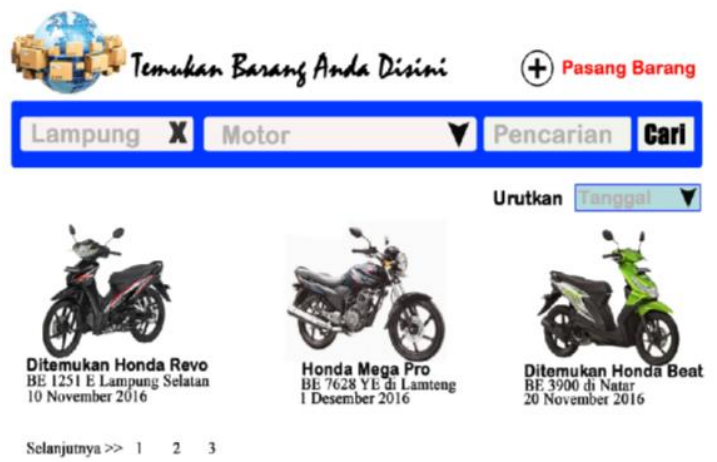

\section{Gambar 4.5. Rancangan Halaman Pencarian}

\section{Halaman Detail Informasi}

Halaman ini akan muncul setelah klik informasi barang. Halaman ini digunakan untuk melihat informasi detail barang yang dicar

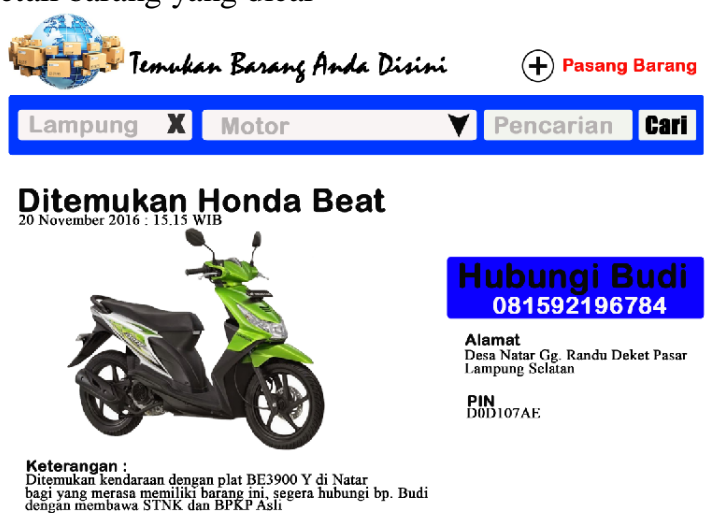

Gambar 5. Rancangan Halaman Detile Informasi

\section{Halaman Informasi Barang}

Halaman ini digunakan untuk melihat informasi barang yang ditemukan dan informasi barang yang dicari

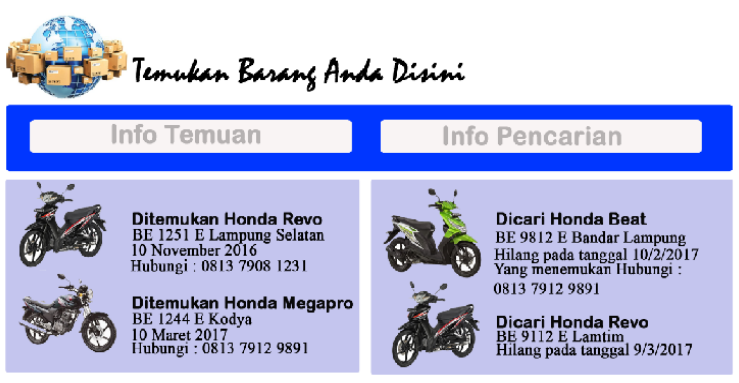

Gambar 6. Rancangan Halaman Informasi Barang

\section{SIMPULAN DAN SARAN}

\section{A. Kesimpulan}

Berdasarkan hasil rancangan yang telah dibuat, maka dapat disimpulkan :

a. Berdasarkan rancangan, maka dapat disimpulkan sementara (hipotesa) bahwa penemu barang akan lebih mudah dalam memberikan informasi kepada pemilik barang

b. Pemilik barang akan lebih mudah dalam mencari barang tanpa biaya yang mahal

c. Rancangan ini dapat digunakan untuk diimplementasi pada aplikasi sebenarnya yang dapat digunakan oleh masyarakat dan pihak kepolisian untuk memberikan informasi kehilangan dan penemuan barang

\section{B. Saran}

Berdasarkan kesimpulan diatas, maka dapat ditambahkan saran untuk melengkapi penelitian yang dapat berupa :
a. Prototype harus dilanjutkan ke tahap implementasi sistem agar dapat digunakan
b. Rancangan dibuat agar lebih ramah dengan pengguna, responsif dan akses cepat
c. Perlu promosi dan cara penggunaan aplikasi

\section{Kontribusi}

Membantu masyarakat untuk menemukan barangbarang dengan lebih cepat dan efisien. Selain masyarakat, dapat digunakan oleh intansi kepolisian untuk membantu menemukan pemilik barang

\section{DAFTAR PUSTAKA}

[1] Ansary AR, \& Frost R., (2003). "E-Marketing Third editon", NeyJersey, Pentice Hall

[2] Anwar M, (2010). "Fiqih Islam", Alma'arif, Subang

[3] Ceri, S. (2002). "Designing Web Application With WebML and Webratio". 221-261. Politecnico di Milano. Springan 
[4] David, Thomas. (2011). "Sistem Pencarian Orang Hilang Berbasis Mobile Web Dengan Social Network Analysis",

[4] Kementerian Komunikasi dan ISSN : 2302-7339 Vol. 11 No. 1(2014)

[5] Ladjamudin AB, (2005). "Analisis dan Perancangan Sistem”. Graha Ilmu, Tanggerang

[6] Leod R, (2008). "Sistem Informasi Management", Salemba, Jakarta

[7] O’Brien. (2005). "Information Management System”. Salemba Empat, Salemba

[8] Potter \& Perry, (1997). "Fundamental Keperawatan”. Salemba, Jakarta

[9] Subhan M, (2012). "Analisi Perancangan Sistem", Lentera Ilmu Cendikia”, Jakarta.

[10] Yuda EF., Rinda C., Bunyamin, 2014. "Rancang Bangun Aplikasi Jejaring Sosial Untuk Berbagi Informasi Kehilangan" ISSN: 2302-7339 Vol. 11 No. 12014 